\title{
Study on the development of civil military integration equipment procurement
}

\author{
Ren Xin ${ }^{1,2}$,Tie-ying WU ${ }^{3}$, Li Yuan ${ }^{4}$, Sheng $\mathrm{Qu}^{5}, \mathrm{Ma} \mathrm{Li}^{1,{ }^{*} \text { Corresponding author }}$
}

1. Naval Medical Research Institute, Shanghai, 200433, China

2. Graduate School, National Defense University, Beijing, 100091, China

3. Oncology Department, The 264th-Hospital of PLA, Taiyuan, 030000, China

4. Maintenance Management Teaching-research Office, Equipment Academy, Beijing, 101400, China

5. Zhuyuan primary school, Shanghai, 200129, China

Keywords: equipment procurement; civil military integration; depth development

\begin{abstract}
This paper discusses the development problems of civil military integration equipment procurement and analyzes the necessity and the main focal point of civil military integration equipment procurement. The equipment procurement institutional mechanism is studied according to the development requirements of military and civilian integration equipment procurement, which can provide reference for the development and construction of civil military integration equipment procurement.
\end{abstract}

\section{Introduction}

The strategic planning of the depth development of civil military integration weapons procurement is put forward, which can lay a solid foundation for improving the efficiency of equipment procurement. Military equipment procurement is the final part of the whole process that is from the demand to the capability of the weapons and equipment, and this work is directly related to its due benefits of the weapon purchase funds. The implementation of military equipment civil military integration procurement is a kind of new strategic thought, and the military equipment procurement construction is integrated into economic and social construction which can play the leading role of the market in the allocation of resources. Through the proactive strategic planning, the construction of military equipment procurement can take a development way with the low input and high efficiency.

\section{The necessity for promoting the development of military and civilian integration equipment procurement}

To carry out the strategy of civil military integration depth development and deepen the reform of equipment procurement system, the competitive procurement should be vigorously promoted to constantly improve the comprehensive benefit of equipment procurement, which has the important significance for preparing for the military struggle and promoting the modernization of national defense and the army. The development and changes of the time should be closely followed under the new situation, the military equipment development law is followed and the development requirements of military and civilian integration is adapted, and the broad social consensus to reform the equipment procurement system continues to be promoted and it is the requirements of equipment procurement reform in a new era.

2.1 Essential attributes of the market economy requires the depth development of military and civilian integration equipment procurement

The basic platform of the civil military integration development is the market, and the basic function of the market is to optimize the allocation of resources through commodity exchange. On 
the one hand, under the guidance of profit and benefit, the market mechanism makes the technology, multi investment and all kinds of forces accumulate to the national defense construction, and on the other hand, it can promote the achievement of national defense construction in the field of economy and society. The basic way of civil military integration depth development of weapon and equipment procurement system is that the equipment procurement should be included in the scope of the market economy and the basic role of the market in the allocation of resources is fully played. However, the current equipment procurement system has not been fully meet the requirements of civil military integration depth development, and it is mainly expressed that the weapons and equipment production and mandatory plan of procurement organization are not suitable for the market competition rule, such as many other equipment manufacturers is not set through competition, equipment procurement sources are severely constrained and so on, which will hinder the free competition of private enterprises and military enterprises. In addition, the price of equipment procurement is not suitable for the requirements of value law, and the implementation of weapons and equipment cost plus pricing and tax policy can easily cause the deviation of the product price from the value, which is not unfavorable for playing the role of the tax leverage use. Therefore, the essence of market economy should be followed in order to promote the depth development of military and civilian integration equipment procurement.

\subsection{Information warfare requires the development of military and civilian integration equipment procurement}

Information warfare is a full range, multi-level, fast-paced three-dimensional war, the combat strength is greatly improved, and the material consumption has increased dramatically. The information war has brought profound changes to the demand of weapon equipments, the demand scale continues to expand, and the quality requirements are greatly improved. The structure of information technology equipment is increasingly complex and the information technology equipment is quickly updated, and the investment demand of weapons and equipment production and procurement will increase quickly, which can provide external power and environment for the depth development of civil military integration equipment procurement. At the same time, the development of information technology in information warfare will increase the equipment integration, and the several separate enterprises will be difficult to meet the practical requirements of equipment support. The diversification of equipment procurement source should be effectively realized, and the reform of deepening civil military integration equipment procurement should be imminent carried out.

\section{The focus on deepening the current development of military equipment procurement integration in order to improve the efficiency of equipment procurement}

Weapon equipment is different from the general commodity, and compare with the civilian production procurement, the requirements is more stringent and the procedure is more complex. To carry out the reform of equipment procurement system, it is necessary to build a competitive environment, use the electronic procurement, improve the equipment procurement standard general level, and strengthen the qualification examination and contract management and equipment procurement personnel training.

\subsection{To build a good competitive environment}

Due to the impact of traditional ideas and decision-making means, a lot of non-military enterprises with military research and production capacity are difficult to get involved in the field of military. In order to make the implementation of civil military integration equipment procurement depth development, firstly, the various measures should be taken to attract and encourage the private enterprises to carry out the competition procurement of weapons and equipment, establish a multi-level and all-round competition mechanism, and through public bidding or Tendering Co. for playing the role of the allocation on the market resources, the expenditure standard of bidding project is further clear and the scope can be expanded to establish science and perfect the bidding system. In a competitive environment, the leading role of the military is fully played, the scope of competition is initiatively expanded, the conditions are created, the multi-channel competitors are 
trained, the monopoly of the industry is broken as soon as possible, and especially the high technical level, law-abiding consciousness non state-owned enterprises with high credibility degree should be selected to participate in the competition so as to constantly improve the procurement benefit of weapons and equipment. At the same time, the competition policies and regulations are established and improved, the healthy development of the competitive environment is promoted, the equipment procurement competition is orderly taken to promote common development of national defense military enterprises, other state-owned enterprises and non state-owned enterprises and improve the competition level of equipment procurement. Secondly, the small and medium-sized enterprises should be actively supported to participate in the procurement competition of weapons and equipment, and the small and medium enterprises mastering technology innovations are actively guided and encouraged to enter the field of military industry in order to form a new military market with many suppliers, and an efficient and flexible procurement environment of the civil military depth integration is established to improve the efficiency of equipment procurement from on the whole.

\subsection{To improve the standards level of equipment procurement}

Technical barriers between the military and the civilian is usually high and the general level is low, and civil enterprises and products cannot easily enter the equipment market. This will make that the choice of equipment procurement become narrow, the level of military and civilian integration is not high, and cannot fundamentally improve the efficiency of equipment procurement. The level of developed country military and civilian integration military equipment procurement is higher, and the one of the main reasons is that the military and civilian products have better versatility. The government standards are subordinated to the standard directory as far as possible based on the national science and technology industrial of civil military integration in order to improve the level of military uniform standards. In order to improve the development level of military and civilian integration equipment procurement, the current military standard system needs to be compressed, and a series of principles can be taken such as civil standards that can meet the military needs to be used, the standards system containing national standards, military standards and industry standard should be established as soon as possible so as to reduce the effect brought by non-unified standards on the depth development of civil military integration equipment procurement.

\subsection{To implement the electronic management of equipment procurement}

With the rapid development of computer network technology and communication technology, e-commerce has been widely used in all walks of life, the civil information technology should be more used in the field of defense procurement, and the development of civil military integration equipment procurement can be implemented. The e-commerce is an important part of procurement reform and a series of feasible measures should be taken, the electronic procurement is used in the process of equipment acquisition, the traditional paper data should be replaced by the digital data, the digital data is effectively exchanged between the procurement departments and industrial enterprises, a various of types of information including technical and statistical data, technical documents, contract documents and management documents should be digitized and standardized by using modern information technology in the whole process of weapon procurement. The network storage, maintenance, integration and exchange are achieved in order to build the integration data environment, by doing this, the weapons and equipment procurement management can be highly integrated and automatic. Business management and collaboration between equipment procurement departments and contractors can achieve the greatest degree of understanding so as to improve the efficiency of the weapon and equipment procurement.

\subsection{To strengthen the qualification review and contract management of equipment procurement}

The competition in weapon and equipment procurement market mainly reflects how to select suppliers in the military procurement department, and in order to strengthen the development of civil military integration weapons and equipment procurement, firstly, the examination management of contractor qualification should be strengthened, the information dissemination should be 
strengthened and the market access and exit system of weapons and equipment for the whole society should be further improved, the qualified manufacturers are regularly published, the weapon development and production manufacturers are invited to participate the strict qualification examination, and through the identification of qualified, banned and unqualified manufacturers list, the strength changes of the contractor are accurately grasped and the list is regularly updated and adjusted. Secondly, the equipment procurement contract management should be strengthened in the development of civil military integration, and this is a kind of important means used to regulate the economic rights and interests of legal between the army and the enterprises. Under the condition of market economy, the equipment purchasing contract content must be comprehensive and contract responsibility must be clear. In order to strengthen the management of equipment procurement contract, it is necessary to turn the focus of procurement management from the final project inspection to the program control system. The production enterprises are constrained through the contract, which can effectively reduce the cost and resistance of the depth development of civil military integration equipment procurement, and the autonomy and creativity can be better to play and eventually the efficiency of military equipment procurement can be improved.

\section{To meet the requirements of the depth development of civil military integration, the construction of equipment procurement system is actively promoted}

In order to meet the requirements of the depth development of civil military integration, the equipment procurement department of the armed forces should grasp the market economy rules and equipment procurement regulations, and the laws and regulations of equipment procurement, the construction of supervision and incentive mechanism regarding the competition as the core, and equipment price approval system construction are all constantly improved. The equipment management agencies and departments must be adjusted and the current military representative management system should be reformed, and the equipment procurement system with a rational structure, the clear responsibility and efficient operation can be gradually formed.

\subsection{To improve the construction of equipment procurement regulations}

With the development of the times and continuous changes of the situation and tasks, some laws and regulations related to the national defense science and technology industry promulgated in the economy era have been unable to fully meet the requirements of depth development of civil military integration equipment procurement. Therefore, the equipment procurement regulations should be further established and improved under the condition of market economy in order to fully play the role of legal advisory services in equipment procurement, and the law enforcement and inspection system construction will be carried out to improve the level of equipment procurement legal system so as to achieve the goals of military and civilian integration equipment procurement depth development.

\subsection{To improve the mechanism construction of equipment procurement management coordination}

The reform of the procurement system involves multi-stakeholder, and the propulsion of civil military integration equipment procurement depth development needs to rely on the promotion of the relevant state departments and the military department. The macro-planning of depth development of civil military integration equipment procurement should be made, the docking of national defense research and equipment development planning and economic development planning is promoted, and the coordination mechanism is improved. The dosage of the resources can be accurately grasped, the repeated construction problems are overcame, the efforts should be made to expand the scope of military cooperation, the specialization production is promoted, and the social forces are fully used and the fair competition platform is established to improve the use efficiency of equipment procurement funds.

\subsection{To improve supervision and incentive mechanism construction of equipment} procurement

The supervision of equipment procurement process needs to be strengthened, and in the process of planning project and bidding, stage conversion, contract formulation and other important matters, 
the equipment procurement should accept the supervision of the discipline inspection, judicial and society to build the civil military supervision system. At the same time, a long-term incentive mechanism of private enterprises on participating in national defense construction should be formed, and the tax system should be reformed and improved. The tax incentives, risk compensation and support object should be increased so as to improve the enthusiasm of private enterprises participating in national defense and military equipment construction and maintain long-term efficient develop momentum of equipment procurement.

\subsection{To improve the construction of equipment procurement price verification system}

Because the weapon is different from the local civilian goods, the procurement of weapons and equipment is very different from the procurement of general civilian products, and in order to achieve effective control of equipment procurement activities, the examination system of weapon equipment price should be constantly reformed. The local supplier must provide the actual price of equipment procurement for the military in order to limit the supplier's excess profits and reach the basic balance of weapons and equipment supply and demand, and the cost of military equipment procurement can be reduced. At the same time, the supplier's benefit demand should be coordinated, the supplier can earn more and maintain the enthusiasm of equipment production, and the long-term innovation and development capabilities can be maintained to promote the depth development of civil military integration equipment procurement.

\section{References}

[1] Yong-dong Liu, Yan-li Feng. Study on the development of military and civilian integration weapons and equipment. Demonstration and research, 2009.

[2] Kai-quan Ma, Hong-qi Deng. The research on the development situation and countermeasure armament of civil military integration construction. Journal of the academy of equipment command and technology, 2011,22 (2): 9-14. 